\title{
Biomass Production from Oil Palm and Its Value Chain
}

\author{
Umana S. Umana ${ }^{1}$, Mbuotidem Sampson Ebong ${ }^{2 *} \odot$, Ekanem O. Godwin ${ }^{2}$ \\ ${ }^{1}$ Department of Geology, University of Calabar, Calabar, Nigeria \\ ${ }^{2}$ Department of Geography and Natural Resources Management, University of Uyo, Uyo, Nigeria
}

Received 10 January 2020; Revised 20 February 2020; Accepted 25 February 2020; Published 01 March 2020

\begin{abstract}
This work examined biomass production from oil palm and its value chain in Nsit Ibom Local Government Area, Akwa Ibom State, Nigeria. This work identified the various biomass products derived from oil palm, the value chain of the various types of oil palm biomass, and the level of utilization of the various oil palm biomass. Ten villages were selected using a simple random sampling method. 380 questionnaires were collected out of 400 that were distributed, which helped in generating data on the level of utilization of the various types of biomass derived from oil palm and the farming practices applied in the cultivation of oil palm. The first hypothesis stated that the level of utilization of the various biomass products derived from oil palm in the Nsit Ibom local government area is significant and was tested using Chi-Square. The second hypothesis stated that the value chain of oil palm biomass is significantly related to the level of utilization in the Nsit Ibom local government area and was tested using Multiple Correlation Analysis. From the test of hypothesis using 0.05 significant, there is a significant impact of oil palm biomass utilization on rural livelihoods in Nsit Ibom LGA. The Multiple Correlation Coefficient of 0.68 shows that there is a relationship between oil palm biomass and utilization in Nsit Ibom LGA. 37.5\% of respondents show that utilization of biomass from oil palm is extremely high. The major biomasses generated are Empty Palm Bunch (EPB), Palm Kernel Meal (PKM), and Palm Pressed Fibre (PPF). The value-added products are categorized into two: food and non-food products. Food products include cooking oil, deep frying oils, margarines and spreads; bakery fats, cocoa butter, alternative fats, confectionary fats, ice cream fats, infant nutrition fats and other food applications; while non-food products include cosmetics and personal care Soaps, candles, pharmaceuticals, lubricants, and agro-chemicals. Therefore, it was recommended that comprehensive training of farmers on palm oil processing technologies should be enhanced in order to enhance the utilization of their biomass.
\end{abstract}

Keywords: Biomass Production, Oil Palm, Utilization; Value Chain.

\section{Introduction}

Palm oil is the world's most important vegetable oil; in 2012 and 2013 palm oil comprised 39\% of total world vegetable oil consumption [1]. It is the third largest export earner in Indonesia, and the industry is estimated to directly employ a total of 7.5 million people in the country. The United Nations Framework Convention on Climate Change [2] defined biomass as non-fossil and biodegradable organic material originating from plants, animals, and microorganisms. This also includes products by product, residues and waste from agriculture, forestry and related industries, as well as non-fossilized and biodegradable organisms. The largest oil palm solid waste biomass is in the

\footnotetext{
* Corresponding author: mbuotisampson@gmail.com

doi) http://dx.doi.org/10. 28991/HEF-2020-01-01-04

$>$ This is an open access article under the CC-BY license (https://creativecommons.org/licenses/by/4.0/).

(C) Authors retain all copyrights.
} 
form of empty bunches with an estimated total of more than 40 million tonnes, followed by waste in the form of trunks of palm trees and midribs with volumes of more than 30 million tons. The biomass waste of the oil palm agro-industry comes from activities in plantations in the form of midrib, leaves, and palm tree trunks. While the palm oil mill produced solid waste in the form of Palm Kernel Shells (PKS), Mesocarp Fibers (MF) and Empty Fruit Bunches (EFB). Malaysia is the world's largest exporter of palm oil, having exported 18 million tonnes of palm oil products in 2011.

The palm oil industry generates a large quantity of waste, whose disposal is a challenging task. This waste can be converted into energy using incineration or other chemical processes. Some companies in Nigeria, such as Presco Nigeria and NIFOR Nigeria, are utilizing this empty palm fruit bunch to generate electricity, which has saved them from the problem of power interruption and minimized cost [3]. The Nsit Ibom local government area has multiple palm species, ranging from local palm nuts to other species locally called agric, it is marketed locally and to neighbouring communities. In the local palm oil plantation, almost $70 \%$ of the fresh fruit bunches are turned into waste in the form of empty fruit bunches, fibers, and shells, as well as liquid effluent. These by-products can be converted to value-added products or energy to generate additional profit for the palm oil industry. In the palm oil value chain, there is an overall surplus of by-products and their utilization rate is negligible [4].

Palm oil has its associated biomass; this biomass in-turn generates residues which are often considered as wastes. Most of the biomass residues from Palm Oil Mills are either burnt in the open or disposed of in waste ponds. In Nsit Ibom local government these waste are seldom used apart from as boilers fuel. These wastes are basically burnt in the palm oil mill. The quantity of solid wastes that have remained unutilized in palm oil mills is significantly higher than the level utilized. Freshly felled oil palm trunks, with their high moisture content, cannot easily be burned in the field. Leaving the trunks in the field without further processing physically hinders the process of planting new crops, as the stem can take about five years to decompose completely [5]. The aim of this study is to examine the biomass production from oil palm and its value chain in the Nsit Ibom local government area. The study was achieved with the following objectives:

- To identify the various biomass products derived from oil palm in the study area.

- To examine the value chain of the various types of oil palm Biomass.

- To examine the level of Utilization of the various oil palm biomass.

\section{Review of Related Literature}

\subsection{Identification of Oil Palm Biomass}

Oil palm industries generate large quantities of oil palm biomass. Biomass is also a biodegradable fraction of products, wastes and residues from agriculture (including vegetable and animal substances), forestry and related industries, as well as the biodegradable fractions of industrial and municipal wastes. Biomass is also viewed as organic matters consisting of carbon, hydrogen, oxygen and nitrogen. Abdulrazzaq et al. (2015) [5] combined a review of secondary materials, interviews with key stakeholders, primary research through surveys and focus group discussions. Both primary and secondary data were collected for this study. The primary data were collected from all key actors in the Palm Oil value chain map by the use of either structured validated questionnaire designed to obtain relevant information regarding Oil Palm Production, or Focus Group Discussion (FGD) with the aid semi-structured questionnaire to collect qualitative data from palm oil processors, wholesalers and retailers of palm oil respectively. While the end users of palm oil data were collected through key informant interview or semi-structured interview. A survey was carried out using a multi-stage sampling method, based the selection of the sample on a combination of two or more sampling methods. The various types are: oil palm trunk (OPT), oil palm frond (OPF), palm oil mill effluent (POME), palm kernel meal (PKM), palm kernel shell (PKS), palm pressed fibre (PPF) and oil palm empty fruit bunch (EFB).

\section{- Palm Kernel Shells (PKS)}

Palm kernel shells (or PKS) are the shell fractions left after the nut has been removed after crushing in the Palm Oil mill. Kernel shells are a fibrous material and can be easily handled in bulk directly from the product line to the end use. Large and small shell fractions are mixed with dust-like fractions and small fibres. Umar et al. (2013) [7] used quantitative approach for data generation. Historical data study of oil palm biomass growth rate between 2004 to 2012 was used and projections at three scenarios (high, low and current status) were made. The findings showed that from the total possible gatherable palm kernel shell derived from oil palm processing mills, only $70 \%$ is utilized effectively. Press fibre and shell generated by the Palm Oil mills are traditionally used as solid fuels for steam boilers. 


\section{- Empty Fruit Bunches (EFBs)}

In a typical Palm Oil mill, empty fruit bunches are abundantly available as fibrous material of purely biological origin. EFB contains neither chemical nor mineral additives, and depending on proper handling operations at the mill, it is free from foreign elements such as gravel, nails, wood residues, waste etc.

According to Chan et al. (1981) [8], he used multiple correlation analysis statistical technique to evaluate the level of biomass in empty fruit bunch. Data on bunch yield, yield components and bunch components were collected from July 2009 to June 2010. Combined analysis was also used to estimate the variance and covariance for the calculation of correlation coefficient and path coefficient values. Empty fruit bunch is saturated with water due to the biological growth combined with the steam sterilization at the mill. Since the moisture content in EFB is around 67\%, preprocessing is necessary before EFB can be considered as a good fuel and manure in farmlands.

\section{- Palm Pressed Fibre (PPF)}

Palm press fibre is a by-product of the extraction of palm oil from oil palm fruits (Elaeis guineensis L.) [9]. This fibrous residue is obtained after the crude oil is separated from the sterilized fruit by means of a screw-press. It may contain important amounts of residual palm oil. Palm press fibre accounts for $10-15 \%$ of the fresh fruit bunch. It can be mixed with empty fruit bunches and kernel shells to be used as biomass fuel: it is one of the main sources of energy to run oil mill plants. According to Bari et al. (2010) [10], data were collected from primary source in which a validated structured interview schedule was used to elicit information from the farmers. Composting palm press fibre with poultry litter and urea has been successfully tested and studies indicate that this compost mixed in sand and loam may enhance crop production.

\subsection{The Value Chain of Oil Palm Biomass}

Value Chain Analysis is a tool that facilitates investigation of business activities in terms of new value adding opportunities in relation to existing values with regards to sourcing of factors of inputs, production, processing and delivery of the finished product. According to Kamahara et al. (2010) [11], the potential for the development of agricultural value chains in Nigeria is substantial and promising, both from the supply and demand perspectives (sufficient natural resources as well as large domestic market opportunities for export). Biomass from oil palm industry has potential to be converted to commercial products such as animal food, fertilizer and absorbent. It can also be converted to biofuel such as bio-ethanol or can be used to generate electricity. Oil palm frond, trunk, and empty bunch can be used as mulching material to help maintain soil humidity and inhibit weed growth, raw material for composting, material for covering plant vegetation, and a source of fiber for various composite products.

\subsection{The Utilization of Oil Palm Biomass}

Palm oil is an edible vegetable oil derived from the mesocarp (reddish pulp) of the fruit of the oil palms, primarily the African oil palm 'Elaeis guineensis', and to a lesser extent from the American oil palm 'Elaeis oleifera'.According to Van Loo and Koppejan (2008) [12], in his work 'Evaluating the Importance of oil palm' with sources of data from the Official publication such as Tree Crop Estate Statistics of Indonesia 2015-2017 (Palm Oil, vol.1), Handbook of Energy \& Economic Statistics of Indonesia Final Edition, stated that Palm oil biodiesel meets the European 'EN 14214' standard for biodiesels. Use of palm oil as biodiesel generates three times the carbon emissions as using fossil fuel and, for example, "biodiesel made from Indonesian palm oil makes the global carbon problem worse, not better." The organic waste matter that is produced when processing oil palm, including oil palm shells and oil palm fruit bunches, can also be used to produce energy. This waste material can be converted into pellets that can be used as a biofuel $[13,14]$.

In Nsit Ibom local government area the wastes resulting from palm oil processing industry still have economical values as they can be used as sources of alternative fuel, fertilizer, chemical compounds, and biomaterials. Oil palm frond [15], trunk, and empty bunch can be used as mulching material to help maintain soil humidity [17, 18] and inhibit weed growth, raw material for composting [16], material for covering plant vegetation and source of raw material for the roofing of thatch houses.

\section{Conceptual Framework}

\subsection{Concept of High Conservation Forest (HCVF)}

The HCVF concept was initially developed by the Forest Stewardship Council (FSC) for use in forest management certification and first published in 1999. Under Principle 9 for FSC certification. High Conservation Value Forests are those areas of forest that need to be appropriately managed in order to maintain or enhance the identified High Conservation Values. A High Conservation Value Forest may be a small part of a larger forest, for example a riparian zone protecting a stream that is the sole supply of drinking water to a community or a small patch of a rare ecosystem. 
The key to the concept of High Conservation Value Forests is the identification of High Conservation Values, because it is the presence of High Conservation Values that determines whether a forest is designated a High Conservation Value Forest. Between 2010 and 2011, Pro-forest carried out HCV assessments of oil palm concessions in Gabon for Olam Palm, in partnership with a qualified local technical team. The assessments included secondary data collection and analysis, remote sensing of forest cover, botanical and fauna surveys, socio-economic surveys, and consultations with local communities and national stakeholders. These combined surveys were used to define and map areas appropriate for the development of Olam's oil palm plantations, and a management plan consistent with the RSPO's requirements for maintaining biodiversity and supporting local livelihoods. In Nsit, this Concept will help in selecting areas that will enhance effective yield in Oil Palm Plantations which will also result to high quantity of biomass from oil palm processing. The high conservation forest concept will also help in reducing the rate of deforestation and habitat loss of critically endangered species in the study area because it will monitor the activities of unauthorized clearing of land for oil palm plantations. The already existing oil palm plantations will be effectively conserved in order to meet sustainable development needs in the study area.

\section{Methods}

\subsection{Research Design}

The study adopted the survey inferential research design. This design was used because it enables relevant information relating to the study objectives to be obtained. The method involved personal observation, structured questionnaire, and oral interviews to obtain information about the level of utilization of oil palm biomass and its value chain as well as proffer sustainable strategies to increase its utilization in Nsit Ibom Local Government Area of Akwa Ibom State.

\subsection{Data Needed}

- Population for Nsit Ibom Local Government Area was obtained from National Population Census (NPC, 2006).

- Data on the level of utilization of oil palm biomass in the selected locations of the study area (Questionnaire).

\subsection{Sources of Data}

In adopting any method in research study, it is imperative to put into consideration the approach that will yield the most productive result relevant to the problem under study. In this regard, the data for the research was derived from the following:

\section{- Data from Respondents in Nsit Ibom Local Government Area by the Use of Structured Questionnaires:}

The use of questionnaire is a major way of getting information from people. In this study, 400 copies of the questionnaires were distributed across the six clans of Nsit Ibom Local Government Area of which 380 questionnaires were collected and used for the analysis.

\section{- Oral Interview:}

In this study, oral interview was conducted among indigenes of Nsit Ibom Local Government Area and their response were collected and also used for the analysis.

\section{- Personal Observation:}

Personal observation formed a vital part of the data collected and analyzed in the course of this study as it helped in having a clear and unbiased data.

Photographs of Information gotten in the Field: Taking photographs in the field is very important as it helped retain information or not misinterpret information. Thus, this study made use of photograph of information obtain in the field.

Published and Unpublished Materials: This study derived his Data from published and unpublished materials about oil palm production from biomass and its value chain in Nsit Ibom local government area such as periodicals, NIFOR article, journals, magazines, internet materials as well as the opinion of experts etc. that were related to the research problem. This helped in knowing the perspectives of other scholars on the research problem and also the extent of existing work that has been done by other scholars on the research problem.

\subsection{Sampling Technique}

The data for this study was collected by employing a simple random sampling technique in selecting ten communities out of the 156 villages in the study Area. (Obotim, Obo Atai, Oboyo Ikot Ita, Ikot Oku Nsit, mbiokporo 1, Afia Nsit, Edebom, Afaha Offiong, , mbiokporo 2, Mbiaso) The reason for this sampling technique was employed 
in order to get accurate response from the respondents. In order to determine the unit of data collected and analyze within the selected villages in the study area, different oil palm mills were studied in Nsit Ibom Local Government Area. The total population of the six communities in the study area base population was projected from 2006 to 2019 with an annual growth rate of $3.42 \%$ (as obtained from National Population Census 2006) using the exponential growth model thus;

$P n=P o(1+n r)$

Where; $P o=$ Base population; $r=$ Growth rate of the population $(3.42 \%$ as obtained from NPC); $\mathrm{n}=$ Time lapse rate in a year.

The projected population was used as a basis of determining the sample size. The total number of the respondents interviewed was determined by expressing the population of the six communities. The Taro Yamane (1973) [19] formula for finite population was employed for equal distribution of the questionnaires across the study Area [20]. The Taro Yamane population sample formula for finite population is given by:

$n=N / 1+N(e)^{2}$

Where; $\mathrm{n}=$ present population; $\mathrm{N}=$ finite population; $\mathrm{e}=$ the level of significance $(0.05)$;

$n=166,898 / 1+166,898(0.05)^{2}=399.03 \cong 400$

Hence, a total of 400 questionnaires were distributed using the random sampling technique. Copies of the structured questionnaires were administered to farmers and other indigenes of the area.

\subsection{Method of Data Analysis}

Both descriptive and inferential statistical techniques were employed in data analysis. The descriptive statistical techniques include the use of tables, figures, etc. to present data collected from the respondents. For hypothesis (1), Chi-Square was used to assess the impact of oil palm biomass on dependent variable (rural livelihood). Furthermore, the hypothesis was tested on a 0.05 level of significance and the decision was taken on the result. For hypothesis (2), Multiple Correlation Analysis was used to determine whether the value chain of oil palm biomass is significantly related to the level of utilization in Nsit Ibom local government area. The statistical technique was relevant as it has established the relationship between oil palm availability in the sampled communities and the level of utilisation. However, oil palm availability (y) in tonnage was used against other variables ( $\mathrm{x}_{1}$ and $\left.\mathrm{x}_{2}\right)$.

\section{Analysis}

\subsection{Data Presentation and Analysis}

This chapter deals with the information obtained on the respondent such as sex, age, marital status, educational level as well as occupation of the respondent. It also involves the testing of hypothesis, discussion of findings and other relevant data gathered from the field study.

Table 1. Analysis of Respondents on the various Oil Palm Biomass

\begin{tabular}{ccc}
\hline Oil Palm Biomass & Frequency & Percentage (\%) \\
\hline Empty Palm Bunches (EPB) & 80 & 20 \\
Palm Kernel Cake (PKC) & 20 & 5 \\
Palm Frond (PF) & 70 & 17.5 \\
Palm Oil Mill Effluent (POME) & 30 & 7.5 \\
Palm Kernel Shell (PKS) & 40 & 10 \\
Palm Press Fibre (PPF) & 40 & 10 \\
Oil Palm Trunk (OPT) & 60 & 15 \\
Palm Kernel Meal (PKM) & 60 & 15 \\
\hline Total & 400 & 100 \\
\hline
\end{tabular}

From the Table 1,80 respondents were of the opinion that empty palm bunches is the commonly used biomass in the study area, 20 respondents on palm kernel cake, 70 respondents on palm frond, 30 respondents on palm oil mill effluent, 40 respondents on palm kernel shell, 40 respondents on palm press fibre, 60 respondents on oil palm trunk and 60 respondents on palm kernel meal. 
Table 2. Analysis of the Level of Utilization of Oil Palm Biomass

\begin{tabular}{ccc}
\hline Level & Frequency & Percentage (\%) \\
\hline Extremely High & 150 & 37.5 \\
High & 100 & 25 \\
Moderate & 80 & 20 \\
Low & 20 & 5 \\
Very Low & 50 & 12.5 \\
\hline Total & 400 & 100 \\
\hline
\end{tabular}

Table 2 above showed that 150 respondents agreed that the level of utilization of oil palm biomass is extremely high, 100 respondents assented that the level of utilization is high, 80 respondents agreed that the level of utilization is moderate, 20 respondents agreed that the level of utilization is low while 50 respondents agreed that the level of utilization is very low.

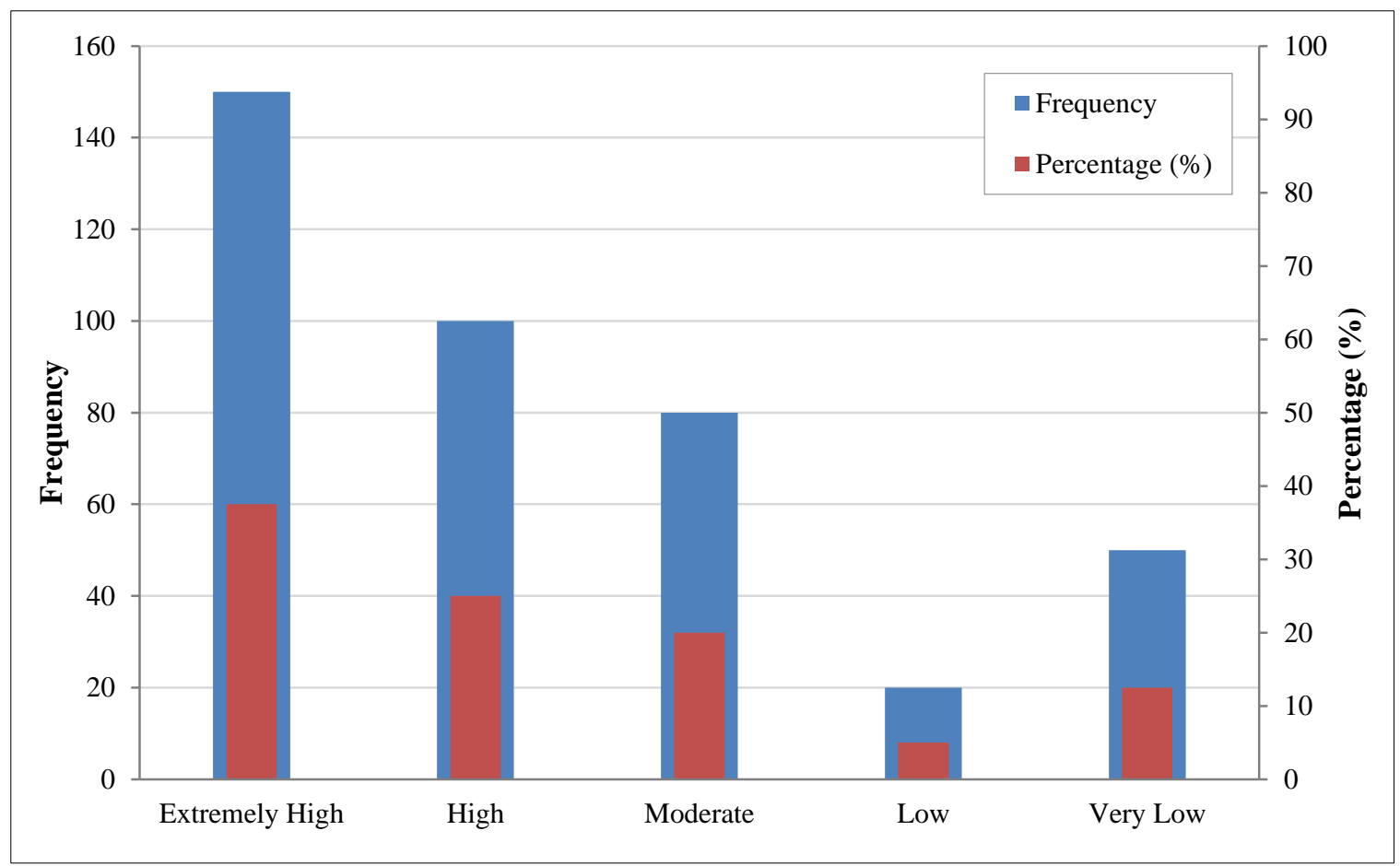

Figure 1. Showing Level of Utilization of Oil Palm Biomass

\subsection{Testing of Hypothesis One (1)}

$\mathrm{H}_{0}$ : There is no significant impact of oil palm biomass on rural livelihood.

$\mathrm{H}_{1}$ : There is significant impact of oil palm biomass on rural livelihood.

Decision: Since the calculated value of 259.87 is greater than the table value of $16.919, \mathrm{H}_{\mathrm{O}}$ is rejected and $\mathrm{H}_{1}$ is accepted. This means that there is a significant impact of oil palm biomass utilization on rural livelihood in Nsit Ibom LGA.

\subsection{Testing of Hypothesis Two (2)}

$\mathrm{H}_{0}$ : There is no significant relationship between biomass availability and level of utilization

$\mathrm{H}_{1}$ : There is significant relationship between biomass availability and level of utilization

Decision: The multiple correlation coefficient of 0.68 implies that $\mathrm{H}_{0}$ is rejected while $\mathrm{H}_{1}$ is accepted which indicate that there is a relationship between oil palm biomass and utilization in Nsit Ibom LGA. 


\section{Discussion of Findings}

\subsection{Findings on the Various Biomass Product derived from Oil Palm}

Oil palm is believed to possess a wide range of biomass products, including empty palm bunches, palm kernel cake, palm frond, palm oil mill effluent, palm kernel shell, palm kernel fibre, oil palm trunk, and palm kernel meal. From the analysis made, findings revealed that 80 respondents were of the opinion that empty palm bunches are the most commonly used biomass in the study area, with 80 respondents, $20 \%$ on palm kernel cake, 70 respondents on palm frond, 30 respondents on palm oil mill effluent, 40 respondents on palm kernel shell, 40 respondents on palm press fibre, 60 respondents on oil palm trunk, and 60 respondents on palm kernel meal.

\subsection{Findings on the level of Utilization of the various Oil Palm Biomass}

In the study area, the level of utilization of the various oil palm biomass varies among the sampled communities. Findings show that palm kernel shell, empty fruit bunch, and palm fruit fiber are mostly used compared to other types of biomass derived from oil palm in the study area. According to an interviewee 'Mrs. Idara', Brooms derived from oil palm fronds are mostly purchased by people than other biomass products derived from oil palm. Palm kernel shells and dried palm pressed fibre are also purchased and used as a source of domestic fuel for cooking. She also noted that the grounded palm fruit is used as animal feed while the empty fruit bunch is used as manure to improve the yield of crops. She mentioned that palm oil mill effluent can be used as biodiesel to power oil palm generating plants.

\section{Conclusion}

Biomass derived from oil palm plays a leading role as a renewable energy source and other useful products for improving the economic, environment and energy safety. Biomass energy has illustrated fewer environmental effects compared to current non-renewable energy production. It has been proven that not only biomass has great potential to supply energy in a cost-effective and sustainable manner, but also air pollution reduction targets could be obtained using the biomass energy from oil palm. Despite the benefits of using biomass derived from oil palm, technical and poor knowledge-based hinders its intensified use. Therefore, there is an essential need to assess, design, and schedule the biomass supply chain to meet all the requirements for having an efficient biomass supply chain. Various methods and approaches have been used to optimize and improve the biomass supply chain stages such as transportation, facilities, and storage. The liquid waste from POME can be used for fertilizer production due to ability to enrich the soil phosphorus, nitrogen and potassium. While the solid wastes can also be converted to a wide range of value-added products that can be clustered into bio-based value-added products such as soap production, probably due to its high potassium content, broom, animal feed, paper production, cream and various bioenergy.

\subsection{Recommendations}

The following recommendations are listed in order to address the issues related to this research work;

- There should be provision of modern processing machinery to alleviate the drudgery of oil palm biomass processors. This could be achieved through acquisition of grants from government, donor agencies or pooling of resources through cooperative formation.

- There should be intensification of adequate or comprehensive training of farmers on palm oil processing technologies in order to enhance the utilization of its biomass.

- The rural dwellers should be educated on the need to commercialize biomass derived from oil palm in order to produce products such as animal feed, soap, etc.

- Oil palm farmers should be encouraged to form cooperatives in order to have access to incentives such as loans, grants etc.

\section{Declarations}

\subsection{Author Contributions}

Conceptualization, U.S.U., M.S.E., and E.G.O.; writing—original draft preparation, U.S.U., M.S.E., and E.G.O; writing - review and editing, U.S.U., M.S.E., and E.G.O. All authors have read and agreed to the published version of the manuscript.

\subsection{Data Availability Statement}

The data presented in this study are available in article. 


\subsection{Funding}

The authors received no financial support for the research, authorship, and/or publication of this article.

\subsection{Institutional Review Board Statement}

Not applicable.

\subsection{Informed Consent Statement}

Not applicable.

\subsection{Declaration of Competing Interest}

The authors declares that there is no conflict of interests regarding the publication of this manuscript. In addition, the ethical issues, including plagiarism, informed consent, misconduct, data fabrication and/or falsification, double publication and/or submission, and redundancies have been completely observed by the authors.

\section{References}

[1] Corley, R. H. V. (2009). How much palm oil do we need? Environmental Science \& Policy, 12(2), 134-139. doi:10.1016/j.envsci.2008.10.011.

[2] UNFCCC Handbook. (2006). United Nations Framework Convention on Climate Change: Handbook. Bonn, Germany: Climate Change Secretariat. Availble online: https://unfccc.int/resource/docs/publications/handbook.pdf (accessed on December 2019).

[3] Hansen, U. E., \& Nygaard, I. (2014). Sustainable energy transitions in emerging economies: The formation of a palm oil biomass waste-to-energy niche in Malaysia 1990-2011. Energy Policy, 66, 666-676. doi:10.1016/j.enpol.2013.11.028.

[4] Oviasogie, P. O., Aisueni, N. O., \& Brown, G. E. (2010). Oil palm composted biomass: A review of the preparation, utilization, handling and storage. African Journal of Agricultural Research, 5(13), 1553-1571. doi:10.5897/AJAR09.016.

[5] Abdulrazzaq, H., Jol, H., Husni, A., \& Abu-Bakr, R. (2015). Biochar from empty fruit bunches, wood, and rice husks: effects on soil physical properties and growth of sweet corn on acidic soil. Journal of Agricultural Science, 7(1), 192-198.

[6] Abdul, H. P. S., Jawaid, M., Hassan, A., Paridah, M. T., \& Zaido, A. (2012). Oil Palm Biomass Fibres and Recent Advancement in Oil Palm Biomass Fibres Based Hybrid Biocomposites. Composites and Their Applications. doi:10.5772/48235.

[7] Umar, M. S., Jennings, P., \& Urmee, T. (2013). Strengthening the palm oil biomass Renewable Energy industry in Malaysia. Renewable Energy, 60, 107-115. doi:10.1016/j.renene.2013.04.010.

[8] Chan, K. W., I. Watson, and K. C. Lim. "Use of oil palm waste material for increased production." Planter 57, no. 658 (1981): 14-37.

[9] Adeoluwa, O. O., \& Adeoye, G. O. (2008). Potential of oil palm empty fruit bunch (EFB) as fertilizer in oil palm (Elaeis guineensis L Jacq.) nurseries.

[10] Bari, M. N., Alam, M. Z., Muyibi, S. A., Jamal, P., \& Mamun, A. A. (2010). Effect of Particle Size on Production of Citric Acid from Oil Palm Empty Fruit Bunches as New Substrate by Wild Aspergillus Niger. Journal of Applied Sciences, 10(21), 2648-2652. doi:10.3923/jas.2010.2648.2652.

[11] Kamahara, H., Hasanudin, U., Widiyanto, A., Tachibana, R., Atsuta, Y., Goto, N., .. Fujie, K. (2010). Improvement potential for net energy balance of biodiesel derived from palm oil: A case study from Indonesian practice. Biomass and Bioenergy, 34(12), 1818-1824. doi:10.1016/j.biombioe.2010.07.014.

[12] Van Loo, S., \& Koppejan, J. (2008). The handbook of biomass combustion and co-firing. Earthscan. Association with the International Institute for Environment and Development, USA. doi:10.4324/9781849773041.

[13] Hambali, E. (2010). The Potential of Palm and Rice Biomass as Bioenergy Feedstock. In 7th Biomass Asia Workshop, November 29-December 01, 2010. Jakarta, Indonesia.

[14] Gatti, R. C., Liang, J., Velichevskaya, A., \& Zhou, M. (2019). Sustainable palm oil may not be so sustainable. Science of the Total Environment, 652, 48-51. doi:10.1016/j.scitotenv.2018.10.222.

[15] Dahlan, I. "Oil palm frond, a feed for herbivores." Asian Australasian Journal of Animal Sciences 13 (2000): 300-303.

[16] Abd-Rahman, R., Kalil Mohd, S., \& Abu Zahrim, Y. (2003). Composting palm oil mill sludge—sawdust: effect of different amount of sawdust. In Proceedings of national workshop in conjunction with ARRPET workshop on wastewater treatment and recycling (Vol. 2).

[17] Abu Bakar, R., Darus, S. Z., Kulaseharan, S., \& Jamaluddin, N. (2010). Effects of ten year application of empty fruit bunches in an oil palm plantation on soil chemical properties. Nutrient Cycling in Agroecosystems, 89(3), 341-349. doi:10.1007/s10705-010-9398-9. 
[18] Rahman, N., Bruun, T. B., Giller, K. E., Magid, J., Ven, G. W. J., \& Neergaard, A. (2019). Soil greenhouse gas emissions from inorganic fertilizers and recycled oil palm waste products from Indonesian oil palm plantations. GCB Bioenergy, 11(9), 10561074. doi:10.1111/gcbb.12618.

[19] Taro Yamane (1973). Population sample formula for finite population, 3rd Edition, Harper and Row, New York, United States.

[20] Khalil, S., Gupta, S., \& Hanif, M. (2018). Estimation of finite population mean in stratified sampling using scrambled responses in the presence of measurement errors. Communications in Statistics - Theory and Methods, 48(6), $1553-1561$. doi:10.1080/03610926.2018.1435817. 